\title{
SLUMLORDISM AS A TORT-A BRIEF RESPONSE
}

Joseph L. Sax*

$P$ ROFESSORS Blum and Dunham begin their comment by accusing us of having a new idea. We plead guilty. ${ }^{1}$ Our purpose was to demonstrate that accepted principles in analogous areas of law would support a slumlordism action, not to argue that tort law as presently applied would do so. Indeed, our basic intent was to underscore the myopia of existing tort law perspectives.

They also charge us with creating a theory which might be used by Mississippi Delta sharecroppers or braceros to attack the "appalling" (their word) situation in which they live; or by those who have been cheated by unscrupulous merchants. We plead guilty again, this time with enthusiasm.2

They balk at a theory that affords a remedy to one subjected to illegally substandard housing if previously he lived in a worse rural dwelling. Their notion seems to be that one who has had "conditioning to a submerged status"3 cannot undergo serious harm from subjection to slum life. It is not apparent how they would define harm, or humiliation, as they call it, but if they think the inhabitants of our urban ghettos are not filled with outrage against slumlords and their fellow mercantilists, or that they are somehow immunized against indignity, ${ }^{4}$ some field research is recommended during the next long, hot summer. The same must be said of their implication that today's urban slumdwellers are only at a temporary way station on the road to some middle-class Valhalla. The culture-of-poverty literature is precisely to the opposite effect, as we expressly noted.5

They ask how we would distinguish the case of landlords who are

- Associate Professor of Law, University of Michigan. A.B. 1957, Harvard University; J.D. 1959, University of Chicago.

1. Indeed, we have done so already; our article expressly noted "that in many ways ours is a radical proposal ... asking the courts to recognize a new tort or at least a much altered form of a traditional tort." 65 MICK. L. REV. 869, 921 (1967).

2. Where Blum and Dunham got the notion that our proposal was "limited to slumlordism in urban slums" we do not know. Our article was written as a detailed application of a general theory to one pressing social problem; it was an illustration rather than a limitation.

3. 65 Mirch. L. Rev. 869, 882 n.64 (1967).

4. Cf. Brown v. Mississippi, 297 U.S. 278, 284 (1996): "It is interesting to note that in his testimony with reference to the whipping of the defendant Ellington, and in response to the inquiry as to how severely he was whipped, the deputy stated, 'Not too much for a Negro." "

5. 65 Mich. L. REv. 869, 902 n.126 (1967). 
not economically motivated but who "make [housing] available free, as a gift." 6 While this would hardly appear to be a problem of mammoth proportions, if they are worried about it, we shall let all such philanthropists slip out of our net.

They also wonder whether the landlord could "purchase the consent of tenants to suffer indignities." We thought it was clear beyond dispute that a central purpose of having housing codes was to assure that landlords could not utilize their dominant economic position to exact acquiesence in living conditions below minimal standards of decency. It hardly seems likely that low income tenants are yearning to make such agreements on their own initiative.

The most puzzling of their objections is the fear that neither a jury (which, they say, embodies "the social conventions of randomly selected citizens") nor a judge ("from the sanctuary of his middle income status") will be able to identify a seriously dilapidated building when they see one. No doubt juries and judges have their problems, but why those problems should suddenly seem insuperable now-and in this particular setting-is difficult to understand. All through history courts and juries have passed on cases of incredible complexity, from railroad reorganizations to drug rites among the Indians; they have had to decide what arouses prurient interests and to give content to every abstract concept from sanity, due process, and gross negligence to ordinary and necessary business expensesyet we are asked to worry that they will not be able to identify a slum dwelling. I think we can rest confidently in the expectation that garbage, rats, and leaking roofs will adequately speak for themselves.

Professors Blum and Dunham are also troubled by our view that one who undertakes to perform a service to advance his own economic interests may be culpable if the service is inadequate. We used as an example the doctor who provides insufficient treatment in order to save himself money, distinguishing that situation from the doctor who merely declines to act as the good samaritan. They assert that the medical analogy is inapposite because a special duty of care has always attached to that profession. This is simply not responsive to our argument, We did not ask that the law apply to a landlord the standards of care of the medical profession. We merely ask that the law hold the landlord to the standards of his profession, which the law already imposes upon him-that is, compliance with the housing codes.

6. 66 MICH. L. REv. 429,456 n.10 (1967). 
They ask how we are to know when a landlord has a defense. We think this is rather easily answered. If the landlord can demonstrate that, despite his attempts to meet code requirements, any of the tenants in the building undermine his efforts by their own misconduct, we would give him a defense, not expecting him to do more than make a reasonable effort toward code compliance. ${ }^{7}$ Blum and Dunham think that, under such a test, the landlord would prevail in almost every case. We have rather more faith in the tenants and their ability to organize for common benefit. We could be wrong, but we ask only that this proposition be tested in application, not in theory.

Much of the remainder of their comment is given over to speculation. How do we know that landlords will not purposely select tenants who are likely to harm the building, in order to avoid future liability? Or that they will not avoid renting to poor people, or that verdicts will not be excessive? Or that landlords will not find ways to become judgment proof? Or that retroactivity problems will not prove unmanageable? We don't, any more than we knew that abolition of the fellow-servant rule or the privity requirement or the development of products liability would not promote intolerably adverse consequences on business. Theirs is simply the argument for never changing anything, for one can never issue a certificate of assurance about the future. We think we have made at least a prima facie case for our proposal. Under such circumstances, one who wishes to argue the impropriety of a new approach to a concededly serious problem has the responsibility to adduce some specific evidence to support his doubts; otherwise, the status quo becomes frozen by the very fact that it is the status quo, since any change could be for the worse.

Blum and Dunham's concern that the tort action may actually reduce the stock of low cost housing misconceives the central point of our article. We are not out to reform the landlord (who, we agree, cannot afford to provide standard housing for the poor); we seek to create a pressure situation leading to additional legislative subsidization of low cost housing. Dislocation of the present housing situation, which is comfortable enough for the slum landlord, is the means for creating that pressure. We recognized in our article that such dislocation involves risks for the tenants, and we only sought to give them the opportunity to decide whether the present housing situation is bad enough to make it worth taking that risk; we hold

7. Naturally such a defense would not be available to a landlord who hired a tenant to undermine tenant organizing efforts. 
to the view that this is a decision tenants ought to be permitted to make for themselves.

The receivership notion must also confront the unprofitability of providing standard quality housing for the very poor. Of course one can put a building in receivership, acquire money for rehabilitation, and then substantially increase the rents. No doubt, as Blum and Dunham note, one can even acquire private investment funds for such a project. But-other than government financed demonstration projects-how many seriously dilapidated buildings housing the very poor have been put in receivership, rehabilitated up to standard, and then re-rented at prices which the previous tenants could afford? That is the real test of a receivership program, and we are still waiting for those statistics. 